\title{
Research on Strategy of the Third Party Logistics Enterprises Customer Relationship Management in China ${ }^{1}$
}

\author{
Weixia Yang \\ Business of Xian International University , Xi'an, China \\ wxyang741117@163.com
}

\begin{abstract}
Keywords: Third party logistics enterprise; Consumer relationship management; Strategy
Abstract. Customer relationship management is a mode of management that emphases meeting the demands to promote the entire enterprise business. The third-party logistics enterprise is an emerging industry, its nature is the service, and it provides services for end-user products and the manufacturer production,provides organization and coordination of services for supply chain. As a service industry, there are many differences from other industries, it pursuit for not short-term effectiveness, but for customer satisfaction and keeping them back. The purpose of improving customer satisfaction, enhancing the competitiveness of enterprises can be achieved not by simple advertising promotions but by customer relationship management. From the need for establishing customer relationship management, this paper analyses a series of problems about the third-party logistics customer relationship management, and puts forward a series countermeasures about customer relationship management.
\end{abstract}

\section{Introduction}

With the speeding up of the progress of global economic integration and exacerbation of market competition, the tradition management mode that takes product and scale as the center has gradually been transformed into the extensive management mode that take the customer as the center, because good customer relationship is an important resource for the survival and development of enterprises in the market competition, of course, it's the same to the third party logistics enterprise. Now strong international integrated logistics companies have accelerated to expanse to our logistics market, to seize market share.In this situation, if the China logistics enterprises have not a good cooperation relationship with their customer, and can not create customer relationship management strategy that is difficult to copy by competitors, it is difficult to achieve a competitive advantage in the market for logistics companies.Therefore, when being confronted with opportunities and challenges, the third party logistics enterprise should adequately recognize the limitations of its customers relationship management strategy, and improve them, which can make them succeed in market well - knownness and good reputation, improve their own competitiveness.

\section{The Significance of Implementation of Customer Relationship Management to the ChinaThird Party Logistics Enterprises}

With the speeding up of the progress of global economic integration and exacerbation of market competition, good customer relationship is an important resource for the survival and development of enterprises. By " customer relationship management " we mean a method and process that gain,maintain and increase profitable customers. The implementation of customer relationship management is meaningful to the china third party logistics enterprises

A. Customer Relationship Management Is Responsible For Improving Customer Satisfaction. Customer relationship management is responsible for improving customer satisfaction and attracting more customers. The third party logistics enterprises may analyze the application 
frequency and the sustainability in order to determine customer loyalty by the customer relationship management, so as to offer service to loyalty partner. By using detailed trade data analysis the third party logistics enterprises may identify which customers remain attractive, and ensure that customers can enjoy the first-class service, so as to win more customers.

B. Customer Relationship Management Contribute to the Logistics Project Smooth Operate. A series of clashes between third party logistics enterprises and customer often occur, that include requirement change collision, information asymmetry collision and logistics project elements collision. These conflicts will lead to arise the distrust between the third party logistics enterprise and customer, shake the basis for cooperation, affect the smooth implementation of the logistics project. When these collisions come to shove,they can cause customer to terminate the project ahead of time, and make both sides suffer huge losses. The two parties can communicate effectively by the customer relationship management, which make customers understand more clearly to the logistics project,and they may develope a kind of mutual trust, mutual respect partnership, so the conflict between them will be resolved. Even if the conflict occur, customers can solute problems with the third party logistics enterprise, and ensure the smooth implementation of the logistics project.

C. Customer Relationship Management Contribute to Enhancing Their Own Competitive. The third party logistics enterprises analyze abundant data by customer relationship management system, and can catch the client's need in real - time. So on the one hand, the third party logistics enterprise offer the appropriate logistics service according to the customer demand in the appropriate time, in order to maintain and attract more customers, improve customer satisfaction and loyalty. On the one hand, by the mutual communication and learning with the customer, the third party logistics enterprises may continuous improve personnel, process and service, and establish organization structure that can response timely to customer requirement changing. Finally these will can improve its competitiveness in the market, and realize its maximum profit.

Through the above analysis, we can learn that the implementation of customer relationship management is very necessary to the third party logistics enterprises.

\section{The Existing Problem of Customer Relationship Management in The China Third Party Logistics Enterprise}

A. Service Levels of the Third Party Logistics Enterprises to Its Customers Is Low. Some of employees of logistics enterprises in china come from the past state-owned warehousing enterprise or from the other professional, most of them have not received specialized training and education, and they lack of deep understanding and awareness about modern logistics,and lack of certain services consciousness. In now ages, logistics activities will require rapid, timely, safe, but some of the logistics enterprises in logistics activities often appear long cycle, high inventory, not up to the requirements of customers, and even the emergence of high damage rate and shortage rate. So the common reaction of service levels of the third party logistics enterprises to its customers is low.

B. The Ability of Collection and Analysis Data About Customer Is Insufficient. In the view of the supply chain, a comprehensive understanding and grasping customer needs, will contribute a logistics enterprises to provide timely and thoughtful service to the customers. But in real operation, the logistics enterprises only can appreciation fixed large customers what type, what preferences, requirements and so on because of long-term cooperation. But for some small customers or new customers, the logistics enterprises rarely care about their preferences, not to mention building the special customer files to recording detaily unit information, contact way, the sale of goods, the evaluation of this service and the contact's name, title, interest, relationship and so on.

C. Customer Communication Channels Is Backward. At present, the logistics enterprises still communicate with customer by the telephone, fax. And efficient use of the network is very little. because of the time factor or the trouble most customers are not willing to take the initiative contact, 
and marketing personnel are lack habit of active contact, so it is difficult to obtain customer feedback, and these make enterprises difficult to grasp the customer satisfaction.

D.The Logistics Enterprises Fail to Provide Personalized Solutions for Customers in Time. In the process of looking for the logistics service providers, customers could not find satisfying service providers in face of many logistics enterprises.One of the main reasons is that the service offered by logistics enterprises is according to the unified standards, so customers did not obtain personalized service.

\section{Analysis of the Existing Problem of the Third Party Logistics Enterprises Customer Relationship Management}

The third party logistics enterprises in China are just at the beginning or the transformation stage, their overall level is not high. A qualitative ascendance do not appear in management level, technical strength and scope of services. Logistics enterprise with truly superior strength and strong competitive is not much. Currently major causes of the existing problem of the third party logistics enterprise customer relationship management are the following aspects.

A. The Cognition Customer Value Is Not Enough for the Third Party Logistics Enterprise. At present, the customer relationship management is used more in communications and finance industry, and it is used few in logistics industry. The awareness of customer value is still in the initial stage for the third party logistics enterprise, and the logistics enterprise has not formed the concept and system. As it turned out, that only a small part of the third party logistics enterprise offers effective communication with customers, forming a long-term partnership with customers, mastering a range of customer resources.

B. Logistics Function and Value-Added Service Offered by The Third Party Logistics Enterprises Are Weak and Single.The value-added services include that loose container loading, relabeling, re-packaging, packaging, classificationt, assembly, testing, repairing and so on. At present, $85 \%$ per cent of their income for the China third party logistics derives from basic services such as transportation and warehousing management. The few logistics like Baogong, Zhonghai has been seen by us in market. And the reason why value-added services is weak is that on the one hand, the third party logistics enterprises more than half of that think that customers do not make outsourcing preparation, and they have the conditions to do their logistics. On the other hand, the customer think that the high level logistics service providers is lack in China.

C. The Scale Is Samll and the Level of Information Technology Is Low For the China Third Party Logistics Enterprises. At present, market share of the third party logistics enterprises in China is not high, so they has not formed a certain scale. The third party logistics enterprise without scale is absolutely impossible to provide low cost and high efficiency in logistics service. In addition, the core of the modern logistics is information technology, because it is the information technology that will link supply chain originally fragmented link together, which reflect the integrated features of modern logistics. In the market in China, the third party logistics can have advanced information technology company is not much, so they is difficult in using information technology widely in warehouse management, transportation management, traffic monitoring, customer management, cargo tracking, contract management, decision analysis of vehicle and personnel management, claims processing, and so on. There are two reasons are followed, the first reason is that the network technology is relatively backward. The second reason is that the cost of covering large network management system is extremely high, even a few large logistics group china felt quite laborious, let alone other small and medium-sized logistics enterprises.

D. There Is Also the Lack of Specialized Talented Person in the Third Party Logistics Enterprises in China. According to a recent reports, few company has option of logistics outsourcing. 
it is due to the lack of excellent logistics talents. There are two reasons for the current lacking of excellent logistics talents in china:

The first reason is that the third party logistics enterprises ignore the introduction of talent. During long-term development, the logistics enterprises are in government's attachment position,so their ideas is backward, awareness of self-development is poor, and they ignored the introduction of talent. Inevitably,the symptoms appear that the entire industry knowledge wear out and lack of talents.

The second reason is that the payment offered to the employee by the third party logistics enterprises is extremely poor in china. As we known that paid is a key factor to retain talent for a company, the payment of logistics enterprises has always been at a lower level. Under the condition of independent choosing profession,talents are reluctant to logistics industry. In contrast, a brain drain is causing.

\section{Strategy in Optimizating the Third Party Logistics Enterprises Customer Relationship Management}

A. To Change Management Ideas. Customer relationship management absorbes the essence of new management thinking,so as relationship marketing, one to one marketing, database marketing and so on. By meeting the special needs of customers, especially meeting the special needs of value customer, The third party logistics enterprises should establish and maintain long-term and stable customer relationship, and provide personalized services, increase customer payment value, improve customer satisfaction and loyalty, and ultimately achieve a win-win situation between third party logistics enterprises and customer.

To form the concept of customer relationship management in the third party logistics enterprises, we must form enterprise culture atmosphere of "all customer centered", must educate and regular train to staff, build a common vision, so that all members can abide by a code of conduct and the value system, set up awareness of providing quality services to the customer, improve service levels.

B. To implete personalized service. First of all, the third party logistics enterprises should build customer files by analysing the customer resources, for example the customer type,customer demand characteristics.Secondly, the third party logistics enterprises should keep the promise to customer. When customers is in the purchase of services, they will face risk including economic benefit, service function, social and psychological and so on. If the third party logistics enterprises make a commitment,they may reduce customer risk as much as possible. Thirdly, the third party logistics enterprises should attention customer feedback. Customer feedback will contribute to achieve business goals of the measure of commitment and to detect the problems appeared in the process of customer service. Complaint is the main way of customer feedback, it is important to maintain the welfare of their clients, to win the trust of customers that the third party logistics enterprises deal with customer complaints correctly. Finally,the third party logistics enterprises should reduce customer costs and improve service level at the same time. When customers select whether self-conducting logistics or the third party logistics, logistics cost is one of the important factors. From a strategic point of view, the third party logistics enterprises should continue to reduce customer costs, achieve win-win cooperation.

C. To Establish Logistics Alliance. With the help of business network that is the result of years of operating, the third party logistics enterprises can combine with other logistics companies, such as traditional logistics enterprises to establish logistics alliance.So it may integrate logistics resources, realize the complementary advantages, provide all-round, multi-channel, integrated logistics service function including railway transport, road transport, water transport, storage, handling, delivery, customs clearance, import and export etc. The logistics alliance is not immutable or frozen., it can be "dynamic alliance", namely after receiving an order from the client, the third party logistics 
enterprises find a suitable partner, and establish "logistics dynamic alliance". After they work together to complete the task orders, order execution, alliance immediately dissolved.

D. To Strengthen the Training of Employees. Personnel who want to improve lability includ the staff and managers. Firstly company should improve ideological quality of an ordinary employee, so it make them really set up the service consciousness.Secondly, company should improve their professional qualifications, so that they can clear the basic theory and the basic knowledge of modern logistics, master skills and techniques of logistics service. As a manager, in addition to lead the enterprise to practice the concept of service, also should grasp the theory and method of managing modern logistics enterprises.

\section{Acknowledgement}

This research was financially supported by the Scientific Research Project of Education Department In Shaanxi Province of China (Grant NO. 16JK2167).

\section{References}

[1] Ying Zhi Yuan,"Enterprise Customer Relationship Management Based on the New Characteristics of International Logistics", Cooperation Economic and Technological, no. 4, pp.57-59, 2011.

[2] Chen Xue,"Research on Construction of the Third Party Logistics Customer Relationship Management System Based on Supply Chain Management", Logistics Engineering and Management, No.2, Pp.34-35, 2011.

[3] Ji Lei "'the Third Party Logistics Enterprise Customer Relationship Management", Operation and Management, no. 6, pp.63-65, 2011.

[4] Wu Hui Jie, “Modern Logistics Enterprisescustomer Relationship Management ”, Enterprise , no. 5, pp.245-247, 2011.

[5] Gong Xian Wen, "Explore on the Customer Alienation Service Strategy of Third Party Logistics Enterprise”, Journal of Chongqing Education College, no. 3, pp.33-36, 2011.

[6] Yu Miao "Reasearch on Implementation of the Third Party Logistics Enterprises Important Customer Relationship Management”, Management Engineer, no. 1, pp.63-65, 2010.

[7] Hou Chun-Lan, “Analyze On The Important Role Of Internal Supply Chain Management In Modern Business Administration”, Modern Information Economy, no.6, pp.24-29, 2012.

[8] Li Ru-Jing, “On Evaluation The Performance Of Supply Chain Management”, Business Economy, no. 10, pp.101-104, 2012.

[9] Li Zhi Yuan, "On the Application of Customer Relationship Management in Logistics Enterprises”, Science and Technology Innovation Herald, no. 9, pp.57-59, 2010.

[10] Zhao Yang, "the third Party Logistics Enterprise Customer Relationship Management ”, Operation and Management, no. 8, pp.57-59, 2010. 